\title{
OBSERVATIONS IN THE SEA ON THE REACTION TO ULTRA-VIOLET LIGHT OF CERTAIN SOUND SCATTERERS
}

\author{
By R. E. Craig and I. G. Baxter \\ Scottish Home Department, Marine Laboratory, Aberdeen
}

(Text-figs. I and 2)

The use of lanterns to attract herring is reported for British waters as early as the fifteenth century (Jenkins, 1927). No such methods are in use here to-day, although in Australia positive results have been reported in the case of pilchard, and in Japan and the Far East the use of light lures has become traditional (Maeda, I95I).

The physiological importance of the ultra-violet component of natural light prompts us to consider it equally with visible light as a possible stimulus. The human eye has become adapted to the red-violet range, centred on yellow, which is the strongest component of the sun's spectrum at the surface. In sea water there is differential absorption so that the centre of maximum intensity is displaced somewhat towards shorter wave-lengths, the precise effect depending upon depth and the nature of the sea water. We should not, therefore, be surprised to find marine creatures sensitive to a range including a portion of the ultra-violet spectrum.

An earlier experiment, using visible light, has already been reported (Parrish \& Craig, 195I). This showed that some organisms producing echotraces are affected by light, and that certain deductions are thus possible about the nature of these organisms.

Ultra-violet light has been known to attract trout and pike ('Reflector', 1949). Experiments on herring conducted off the Belgian coast by the Netherlands research vessel, however, did not lead to definite results (de Boer, 1950). A number of experiments have been carried out on the East Coast during the past summer, by $\mathrm{Mr}$ Parrish and the present authors. In these an ultra-violet lamp was lowered where echo-traces were found. The traces were of various ill-defined forms, but included a typical shallow scattering layer. No reaction was observed in any case.

We report here two experiments in which positive results have been obtained using the ultra-violet light.

The source was a I25 W. 'black' ultra-violet lamp housed in a vertical glass cylinder with cast-iron ends. The horizontal intensity is therefore much 
greater than the vertical, and the upward and downward components are not dissimilar. When this lamp is lowered at night to a few fathoms depth in the summer sea, it produces at first no visible illumination. After about $5 \mathrm{~min}$. a violet glow is visible in the surrounding water, and this intensifies until it can be seen to extend 3 to $4 \mathrm{~m}$. from the lamp, the shadows of the lamp bolts cutting clear lanes through the luminescence. We take this to indicate that numerous fluorescent organisms are attracted by the light, though these have not yet been identified. The gathering of such a mass of small organisms may obviously affect the behaviour of their predators, and in work such as this it is necessary to distinguish between such secondary effects which must take some little time to develop, and immediate reactions to switching on of a light, which must presumably imply direct visual stimulus. The switching off of the lamp, however, is a visible event even to the human eye since the distinct luminescent glow vanishes abruptly.

Traces in Figs. I and 2 were obtained on board the R.V. Clupea, using a Kelvin and Hughes recording echo-sounder, type MS 22.

Recording I (see Fig. I). Position: 7 miles S.E. $\times$ S. from Stornoway in $100 \mathrm{~m}$. of water. Recording begins $20.10 \mathrm{hr}$. and ends $22.00 \mathrm{hr}$. 25 September I95I. Sky overcast, no moon. The ship is lying to drift nets.

A confused trace with a peculiar 'saw edge' appearance to its upper position extends from 20 to $60 \mathrm{~m}$. depth, and the lamp is lowered into the centre of this to a depth of $35 \mathrm{~m}$., appearing on the recording as a distinct horizontal line. Some avoiding action is evident and then the trace increases in density around the lamp. When this is switched on separation takes place into two distinct traces, the upper lying between 8 and $\mathrm{I} 4 \mathrm{~m}$. above the lamp, and the lower between 6 and $14 \mathrm{~m}$. below it. The upper trace consists of crescents each of which may be attributed either to a single subject or to a small distinct group, the lower is of homogeneous appearance and may represent a more uniform distribution of scatterers (though it must be remembered that greater depth in itself gives a more uniform appearance to any distribution of this kind, owing to the larger cross-section area of the supersonic beam). We consider this lower trace to be similar in cause to the scattering layers described by Burd \& Lee (I95I) and Parrish \& Craig (I95I).

Half an hour later, after sampling has been carried out with the Hensen net to $38 \mathrm{~m}$., the lamp is raised to $20 \mathrm{~m}$., whereupon the lower trace rises, maintaining a constant depth below the light, and the upper trace descends to merge with the lower, forming a dense trace in which the components are not readily separable. Ten minutes later the light, still switched on, is lowered rapidly to $50 \mathrm{~m}$., driving before it some fast-moving organisms, and then to $80 \mathrm{~m}$. at which depth it is out of range of the echo-sounder and the trace returns above it. In this connexion it must be remembered that the space close to the light, which is devoid of scatterers, is probably in the form 


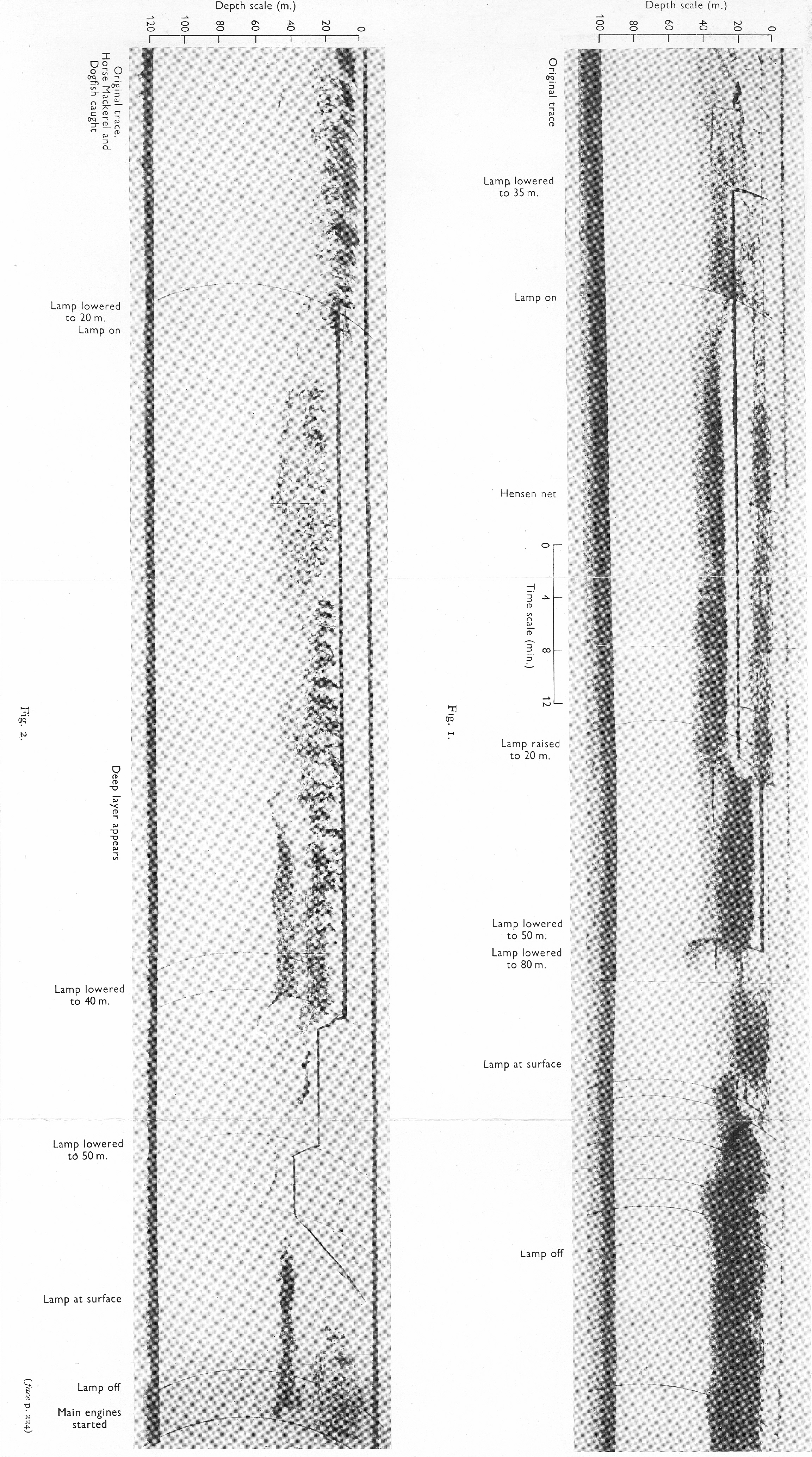


of a sphere, and that to the side we have presumably an undifferentiated layer of scatterers. The reappearance of the shallow trace may therefore be explained as a horizontal concentration of organisms, and does not necessarily imply the return of those forced down by the light. Finally the lamp is raised slowly to the surface and remains there for a while switched on. The trace reappears as a very dense band between Io and $40 \mathrm{~m}$., and remains thus even after the lamp is switched off. An attempt to affect this trace by directing the beam of an Aldis signal-lamp downwards through the water produced no certain reaction. The rate of apparent vertical movement of the lower (homogeneous) trace may be stated with reasonable accuracy as: descent, $3 \mathrm{~m}$./min.; ascent, $5 \mathrm{~m}$./min. The rate of movement of the upper (heterogeneous) trace cannot be accurately assessed, but it is clearly much greater than this.

The Hensen sample revealed that copepods were abundant, euphausids, decapod larvae and Sagitta common, and others present in small numbers included pteropods and hyperiids. This is not significantly different from other plankton hauls in the Minch at this season.

The drift net catch consisted of 39 herring, 24 common mackerel, I horse mackerel, 5 young dogfish and I whiting, and the trace originally observed was within reach of these nets, so we can feel certain that these are not caused by abundant adult herring. Fishing with 'dandy' lines and with baited hand-lines throughout this experiment produced no result.

Recording II (see Fig. 2). Position: 6 miles S.E. from Stornoway in $120 \mathrm{~m}$. of water. Recording begins $20.50 \mathrm{hr}$. and ends at $22.30 \mathrm{hr}$. I October I95I. Clear sky, no moon. The ship is again lying to drift nets.

A peculiar jagged trace is observed superimposed on one of spotty appearance, each of these extending roughly from 8 to $30 \mathrm{~m}$. depth. A few illdefined marks appear below this. The 'jags' are caused by objects rising very uniformly at about $\mathrm{I} 4 \mathrm{~m}$. $/ \mathrm{min}$. and these are not seen descending. They could be caused either by gas bubbles, or by fish swimming up under the ship and then away horizontally. The former would appear to be a more probable explanation ${ }^{1}$ and presumably indicates the presence of physostomatous fish. Catches of horse mackerel (Caranx trachurus) and dogfish (Squalus acanthias) were obtained at this position using a 'dandy line' which carries a series of bare hooks.

When the lamp is lowered into the centre of the trace some avoiding action is apparent, and when it is switched on, the trace disappears for about $3 \mathrm{~min}$. and then begins to re-form under the light, the spotty component returning first, followed after a lapse of another Io min. by heavier markings

1 The literature on the rising velocity of bubbles has been summarized by Worster (I948), and reference to his figures show that for bubbles between 0.04 and $\mathrm{I} .4 \mathrm{~cm}$. diameter, the rate of rise is roughly independent of size, and is of the order of $15 \mathrm{~m}$./min. This would appear to confirm our conclusion. 
which may be caused by the same fish as the original jagged trace but no longer rising. Some $I_{5} \mathrm{~min}$. later two components can still be distinguished, the lower homogeneous one maintaining a depth of about $20 \mathrm{~m}$. below the lamp, whilst the top of the upper is at exactly the depth of the lamp. This might be explained as a reorganization within the layer, but the appearance is more suggestive of the arrival on the scene of fresh recruits.

By $21.55 \mathrm{hr}$. the lamp has been at the $20 \mathrm{~m}$. mark for $50 \mathrm{~min}$., and it is then lowered to $40 \mathrm{~m}$. and subsequently to $50 \mathrm{~m}$. In a period of the order of I sec. from the first movement of the lamp, the topmost of the organisms producing the lower trace either descend $12 \mathrm{~m}$. or remove themselves horizontally from the scene of action. The lower organisms appear to descend more sedately, remaining at a constant depth below the lamp, and then disappear. The upper layer maintains its distance below the lamp, and also fades out.

The lamp is then hauled slowly to surface and remains there switched on for a time. The lower trace reappears at $50 \mathrm{~m}$. depth and remains there, and the spotty trace re-forms. The immediate effect on the lower trace of the sound of starting up the main engine is of interest.

The drift net catch consisted of $3 \mathrm{I}$ herring, 44 horse mackerel, 24 common mackerel and 77 dogfish, and we can therefore exclude abundant adult herring as the cause of the upper water trace, although not as a possible cause of the lower one which is below the reach of the nets. In fact, the speed of reaction to stimulus of the latter is highly suggestive of herring or other active fish.

These experiments are not by themselves conclusive, and it is particularly unfortunate that the underwater camera was not available on this cruise. When we lay the evidence alongside the work of many other investigators, however, we can suggest associating the traces as follows:

(I) Recording I

(2) Recording I

(3) Recording II

(4) Recording II

(5) Recording II

\begin{abstract}
Upper trace
Lower trace

Spotty trace

Jagged trace

Deep trace
\end{abstract}

\author{
Fish, unidentified \\ Plankton organisms, unidentified \\ Dogfish \\ Horse mackerel \\ Probably herring, though whiting \\ or other adult fish are a possible \\ cause
}

It will be seen that results such as these are of intrinsic biological interest in that reactions to light can be measured using the echo-sounder. They also give hope of deriving ultimately a set of tests which would be of commercial value by giving greater certainty in the identification of the causes of echo traces. For both these reasons, experiments of this type will continue during the present year. 


\section{SUMMARY}

Two experiments on the reaction to ultra-violet light of certain sound scatterers in the area are described.

The source was a I25 W. ultra-violet lamp.

The scatterers were detected using a Kelvin and Hughes recording echosounder, type 22 .

The traces on both occasions were of the confused type caused by a number of different organisms, apparently lying between 20 and $60 \mathrm{~m}$. and 8 and $30 \mathrm{~m}$. respectively.

The responses of the different organisms to the ultra-violet light as shown by the components of the traces are described and their speeds of reaction calculated.

The types of organisms causing the traces are suggested.

\section{REFERENCES}

BoER, P. A. DE, I950. Ervaringen met het echolood tijdens de ijle haringteelt op de Belgische kust. Visserij-Nieuws, Vol. 2, No. II, p. I27. (Summarized in World Fisheries Abstracts, Vol. I, No. 4, July-August, 1950.)

Burd, A. C. \& LEE, A. J., I95I. The sonic scattering layer in the sea. Nature, Vol. I67, p. 624 .

Jenkins, J. T., I927. The Herring and the Herring Fisheries. I63 pp. London.

Maeda, H., I95I. Analytical studies of marine lamp communities. Publ. Seto Mar. Biol. Lab., Vol. I, No. 4.

Parrish, B. B. \& Craig, R. E., I95I. Sonic layers in the sea. Nature, Vol. r68, p. 472.

'Reflector', I949. Views on the News. Electrical Rev., Vol. 145, p. 787.

WORSTER, R. C., I948. On the rising velocity of air bubbles. British Hydromechanics Research Association, Tech. Note, No. I. 